\title{
ARTIGOS
}

\section{Por uma Geração Fervida ou onde o fervo encontra a contracultura- tropicalista e o soul}

\section{유드태}

Vinícius Alves da Silva ${ }^{1}$

Resumo: O presente artigo propõe uma reflexão em torno da ideia de uma Geração Fervida como uma aposta frente ao atual momento de avanço da chamada Nova Era fascista no Brasil. Acreditamos que a Geração Fervida, enquanto ideia, pode servir como forma de aquilombar diferentes linhagens que produzem resistência e organização a partir do uso político de festividades urbanas. Para fins analíticos separamos duas grandes linhagens que consideramos determinantes, neste momento, na construção de uma geração fervida: as herdeiras da contracultura-tropicalista e as herdeiras do movimento soul. Esse artigo, portanto, tem o objetivo de construir um esforço para o sentido de refletir possibilidades de diálogo e composição entre as diferenças dessas linhagens e produzir, com isso, fundamento para um conector geracional, que nos sirva, estrategicamente, como forma de aglutinar uma nova centralidade de poder.

Palavras-chaves: fervo; contracultura; tropicalismo; soul;

Abstract: This article proposes a reflection around the idea of a Fervida Generation as a bet in the face of the current moment of advancement of the so-called fascist New Age in Brazil. We believe that the Fervida Generation, as an idea, can serve as a way of combining different lineages that produce resistance and organization from the political use of urban festivities. For analytical purposes, we separated two great lineages that we consider decisive, at this moment, in the construction of a fervida generation: the heirs of the counterculture-tropicalist and the heirs of the soul movement. This article, therefore, has the objective of building an effort towards reflecting possibilities of dialogue and composition between the differences of these lineages and producing a foundation for a generational connector, which serves us, strategically, as a way of bringing together a new centrality of power.

Keywords: fervo; counterculture; tropicalism; soul;

\footnotetext{
${ }^{1}$ Diretor Geral da Associação Beco das Cores - Educação, Cultura e Cidadania LGBT, Bacharel em Estudos de Gênero e Diversidade (UFBA), mestrando do Programa de Pós-Graduação em Estudos Interdisciplinares em Mulheres, Gênero e Feminismo (PPGNEIM-UFBA) e integrante da Feminaria Musical: grupo de pesquisa e experimentos sonoros (EMUS-UFBA).
}

Vol. 02, N. 04, Out. - Dez., $2019 \cdot$ www.revistas.unilab.edu.br/index.php/rebeh 
Por uma Geração Fervida ou onde o fervo encontra a contraculturatropicalista e o soul

\begin{abstract}
"Escrevo essas linhas sem medo de como você pode interpretar / Um chamado / Tá tudo acordado / O bonde tá forte, nóis veio cobrar / Do ouro ao conhecimento / Não vai ter lamento e eu vou te mostrar / Minha história é contada oralmente / Não adiantou cê querer apagar / De boca a boca nóis vamo contando um levante e armando para dominar / Seus livros, seus filmes, sua casa, seus filhos e a televisão que cê vê no seu lar / Mexendo com gentes, plantando sementes, germinando mentes, logo vai brotar / Vai virar floresta, não vou deixar fresta pra minha história você contestar / Entrei nas escolas e nas faculdades / Igrejas não vão mais me silenciar / Aqui não é teu culto nem congregação / Nessa mata fechada cê não vai entrar / Fazendo esse alarde pois não sou covarde / Não vai nem dar tempo, o plano tá em ação / É ação direta, sai da minha reta / É mais do que só gritar revolução / Sou psicopreta, tomei sua caneta, sou bem mais que teta, bunda e corpão / Sou mente afiada, festa tá armada, fogos de artificio, segura o rojão!

O Chamado - Bia Ferreira (2019), cantora e compositora mulher preta sapatão
\end{abstract}

\title{
Introdução
}

Fervidas, do novo mundo, aquilombai-vos! É chegado o momento de enfrentar a Nova Era anunciada pelo Governo da República Federativa do Brasil contra nós. O paradigma evangélico-conservador-fascista-racista-LGBTIfóbico-machista-latifundiário-milicianomilitarista-coleaquioseugrupodeopressor, que construiu uma ampla aliança eleitoral, capaz de ganhar as eleições em 2016 e 2018 e produzir um discurso de ódio contra nossas vidas, precisa ser derrotado no Brasil em sua dimensão filosófica, cultural e política. Ou, em outras palavras:

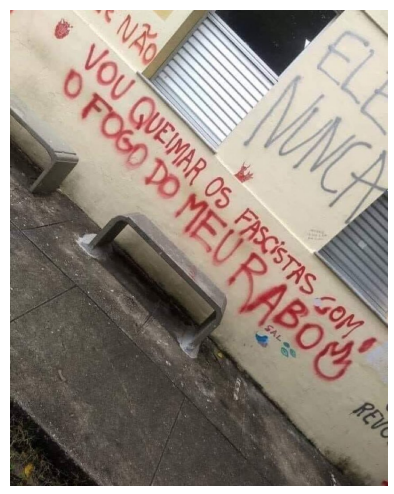

Imagem 1 - na foto lê-se "ele nunca. vou queimar os fascistas com o fogo do meu rabo"2

Embora sejamos muitas, as que concordamos com a chamada acima (ou mesmo com a imagem que a ilustra), seguimos comumente nos questionando sobre a capacidade dessa nossa

\footnotetext{
${ }^{2}$ Foto disponível na internet a partir do endereço https://goo.gl/images/EvfLgK, acessado em 26 de março de 2019.
}

Vol. 02, N. 04, Out. - Dez., $2019 \cdot$ www.revistas.unilab.edu.br/index.php/rebeh 
força de colocar abaixo a Nova Era. Como derrotar o paradigma atual que parece ter vencido não somente as eleições, mas as possibilidades de seguirmos construindo nossos sonhos e planos juntas, juntos e juntes? Onde nos encontramos para voltar a sonhá-los e planejá-los de RE Clmaneira mais coletiva? Ou, como identificamos potência e capacidade aglutinadora em torno '(TILC들

Propomos aqui uma reflexão em torno da ideia de uma Geração Fervida. Explicaremos de maneira breve nos tópicos seguintes como chegamos a este conceito, que na verdade é uma aposta frente ao atual momento. Acreditamos que a Geração Fervida, enquanto ideia, pode servir como forma de aquilombar - conceito que também explicaremos mais adiante - diferentes linhagens que produzem resistência e organização a partir do uso político de festividades urbanas. Para fins analíticos separamos duas grandes linhagens que consideramos determinantes, neste momento, na construção de uma geração fervida: as herdeiras da contracultura-tropicalista e as herdeiras do movimento soul.

Ambas experiências surgidas no Brasil tiveram forte influências de vertentes globais como a contracultura (para a contracultura-tropicalista) e o movimento da soul music norteamericana (para o movimento soul). Ambas conectaram, nos anos de 1970, um conjunto de pessoas, sobretudo jovens universitários, mas também alguns das classes mais empobrecidas que ouviam as letras das músicas e refletiam a partir dela um outro modo de vida.

Esse artigo, portanto, tem o objetivo de construir o esforço nesse sentido: refletir sobre possibilidades de diálogo e composição entre essas duas linhagens e produzir, com isso, fundamento para a ideia de uma geração fervida, como forma de aglutinar uma nova centralidade de poder (NASCIMENTO, 1985) capaz de acumular para o horizonte de derrocada da Nova Era Fascista. Apresentarei nos tópicos seguintes algumas reflexões e fundamentos em torno do que estou propondo aqui. Tomo como referência o estudo que desenvolvi sobre o Fervo na conclusão da Graduação como Bacharel em Estudos de Gênero e Diversidade, que me permitiu caminhar na literatura da contracultura-tropicalista e do soul, trazida por meio da interlocução ao longo da pesquisa etnográfica com pessoas que parecem manter os ideais dessas duas linhagens vivas, de diferentes formas, hoje.

\section{Aquilombar a esperança fervida: é disso que estamos falando!}

Em 1985 a professora Beatriz do Nascimento já afirmava que o Quilombo (Kilombo) [...] representou na história do nosso povo um marco na sua capacidade de resistência e organização (NASCIMENTO, 1985:2006 p. 117). A memória histórica resgatada por 
Nascimento nos mostra que Quilombo (Kilombo) teve diferentes significados em Angola, sobretudo para a sociedade Imbangala ou Jagas - sociedade guerreira que lutava contra a investida colonial-escravista portuguesa (NASCIMENTO, 1985). Kilombo ou Quilombo teve RE Clo significado (a) tanto para denominar o acampamento de escravos fugitivos; (b) quanto o '는든.

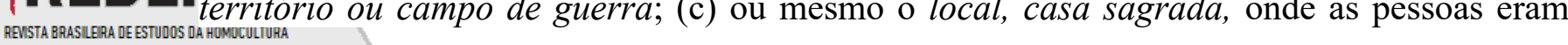
iniciadas (em um processo de circuncisão) na sociedade Jaga, sobretudo os jovens que eram adotados das tribos que eles derrotavam; (d) ou, ainda, os próprios indivíduos ao se incorporarem à sociedade angolana Imbangala (idem).

O que melhor nos serve no conceito de Quilombo (Kilombo) proposto pela sociedade Jaga é a ideia de que ele, o Kilombo, era uma instituição social responsável por cortar transversalmente as estruturas de linhagem e estabelecer uma nova centralidade de poder frente às outras instituições de Angola (NASCIMENTO, 1985:2006 p. 119). Em outras palavras, o Quilombo era responsável por unir, a partir da iniciação nesta sociedade, em seus valores e princípios, diferentes linhagens de tribos e o faziam com o nítido objetivo de resistir e organizar uma nova centralidade de poder (idem).

Figuras como Erica Malunguinho são um bom exemplo quando o sentido é organizar uma nova centralidade de poder - que ela também tem chamado de novo marco civilizatório. Arte, cultura e politica, disse ela em sua fala poética em cima do mini-trio na $1^{\text {a }}$ Marcha do Orgulho Trans* de São Paulo (2018). No chão, abaixo do trio, onde nós éramos uma multidão sexodiversa, ouvia-se os tambores do Bloco Afro Ilu Inã - o mesmo utilizado por ela no cortejo realizado para sua chegada até a ALESP no seu ato de posse como parlamentar em 2019. Érica é a primeira trans negra nordestina eleita Deputada Estadual em São Paulo, mesmo com toda falta de priorização dada pela direção do Partido Socialismo e Liberdade (PSOL) à sua campanha.

Ela é ainda a idealizadora de um local conceituado como quilombo urbano, um espaço localizado na Rua Apa, Barra Funda, em São Paulo capital, denominado Aparelha Luzia. A operação política girada em torno do Aparalha Luzia, em si, merece uma observação mais cuidadosa e aproximada. Contudo, não temos dúvida de que os 55.223 votos que ela teve nas eleições em 2018 são também fruto da capacidade que teve em aquilombar no Aparelha um conjunto de encontros e relações, para disputar esse novo centro do poder. Malunguinho tem chamado o seu gabinete de mandata quilombo.

Assim como Malunguinho nos falou em São Paulo, vimos o slogan arte como luta, ser utilizado pela organização do IC - Encontro Internacional de Artes realizado em Salvador no ano de 2018. Percebemos aí o uso recorrente da ideia de arte como ferramenta para engajar Vol. 02, N. 04, Out. - Dez., $2019 \cdot$ www.revistas.unilab.edu.br/index.php/rebeh 
pessoas ligadas às suas diferentes linguagens em processos de luta social e política. Ao mesmo tempo, também nos pareceu ser uma recorrente mensagem para nos mostrar a necessidade de reconhecer outros pontos de partida que diferentes setores da sociedade estão nos convidando RE Cla considerar (novamente) neste momento da história.

'(IILCLCIT)' Este ponto de partida, que toma arte, luta, cultura, política e festa como substantivos valiosos, bebem de importantes fontes históricas úteis à resistência em diferentes períodos. Destacamos duas fontes, as quais denominaremos aqui de linhagens, que consideramos determinantes: a contracultura-tropicalista e o movimento soul. Antes disso é importante destacar que escrevi sobre a defesa do fervo ${ }^{3}$ (SILVA, 2018) considerando-o (o fervo) enquanto um circuito de deslocamentos em torno de espaços e festividades urbanas politicamente engajadas em propósitos sociais e políticos (SILVA, 2018, p. 47). A partir dele pude estar em contato com diferentes festividades e circuitos que me remetiam ora a linhagem da contracultura-tropicalista ora aos herdeiros(às) da cultura do movimento soul. Neste sentido, passei a pensar qual contribuição daí poderíamos apreender para pensar uma geração política fervida. Ou melhor: onde essas experiências se tangenciam? E, qual a projeção coletiva que estas experiências trazem?

Minha pesquisa, que durou entre 2016 e 2018, me fez circular e estar em contato com festividades como Afrobapho, Batekoo e TOMBO. Nela puder perceber um protagonismo na organização e na participação de jovens negras(os), mulheres e LGBT, de e com trajetória de periferia. Em sua imensa maioria (74\%), elas tinham, em 2016, até 24 anos de idade e eram oriundas de mais de 30 bairros diferentes da cidade de Salvador, além de cidades da região metropolitana como Lauro de Freitas ou Camaçari. O contato com essas produções e essas pessoas me fez percebê-las (festas, pessoas e as relações estabelecidas aí) de uma outra forma. Ao sombreá-las da ideia promovida pelo Rico Dalasam, rapper, gay e negro de São Paulo que nos disse que "o fervo é protesto" (DALASAM, 2015), acredito ter contribuído para construção de uma narrativa etnográfica potente envolvendo festa, participação social e pertença cidadã, tudo isso, sem perder um compromisso de fundo que originou a pesquisa que era o de buscar responder ao aumento das novas infecções de HIV/AIDS entre jovens de 15 a 24 anos no Brasil.

A festa à brasileira, tese de Rita de Cássia Amaral datada de 1998, é uma referência para a produção acadêmica neste campo no Brasil (1998). O estudo é citado em produções de outras pesquisadoras (MIGUEZ, SILVA, 2014; PEREZ; 2011) que também fazem da festa

\footnotetext{
${ }^{3}$ Em defesa do fervo: olhares etnográficos sobre a produção de cuidado no contexto de festas urbanas em Salvador-Bahia-Brasil foi o título do meu trabalho de conclusão de curso na Graduação em Estudos de Gênero e Diversidade da Universidade Federal da Bahia.
}

Vol. 02, N. 04, Out. - Dez., $2019 \cdot$ www.revistas.unilab.edu.br/index.php/rebeh 
objeto de atenção e reflexão no campo científico. Amaral defende que a festa "à brasileira" constitui uma mediação entre diferentes dimensões culturais, categorias e símbolos (AMARAL, 1998, p. 09). Ela nos traz referências que ajudam a perceber como a festa já é RE CIpresente em textos de autores reconhecidos como Durkheim (1912; 1968) e Freud (1913;

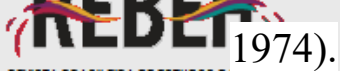

A ideia da festa como mediação é trazida no estudo por meio de referências que remontam ao período colonial. Amaral entende que a relação estabelecida entre a Coroa e os colonos por meio de diferentes festividades era fruto de uma mediação privilegiada por conter em si a síntese de mediações diversas. Neste sentido, a festa se mostrou, no período colonial, como tradução, ponte forte entre culturas, já que todas elas conheciam e compreendiam, apesar da diversidade, este termo universal (AMARAL, 1998, p. 10). Ela nos permite perceber como desde então e ainda hoje:

o interesse geral dos brasileiros pela festa, momento de liberdade e ultrapassamento de limites, [existe] já que tanto negros escravos, índios e outros grupos menos privilegiados participavam dela, descobrindo ou forçando pequenos espaços para sua inclusão e a de seus valores na cultura em formação. (AMARAL, 1998: p. 10).

Ou, como escrevi na Defesa do Fervo:

A partir das análises apresentadas pelo estudo de Amaral é possível entender que a festa cumpriu importante papel no jogo da mediação cultural e com isso no estabelecimento das relações de poder. [...] Por um lado (a festa) esteve a serviço da cultura católica europeia, por meio da celebração de seu calendário religioso, servindo como um auxílio na subordinação dos povos indígenas ou das(os) negras(os) traficadas(os) como escravas(os). Por outro lado, a inclusão de valores das(os) negras(os) escravizadas(os) e das(os) índias(os) na cultura brasileira em formação (AMARAL, 1998, p. 10) também se apresentava como parte do jogo, utilizando muitas vezes do circuito oficial das festividades da coroa para ganhar visibilidade sobre si e suas necessidades. (SILVA, 2018: p. 51)

Já existe vasta literatura, como vimos acima, para considerar as festas como local privilegiado da mediação de culturas. Arrisco dizer que as festas promovidas pelo fervo, circuito que se organiza festivamente promovendo um certo engajamento político de uma geração política, nos permitem pensar na produção de uma nova centralidade de poder a partir dele. Dando materialidade a minha hipótese, eu acredito que fervos como a Batekoo e Afrobapho, que reivindicam uma referência no que foi a cena do Soul (seus bailes blacks e todo empoderamento e representatividade trazidos na afirmação positiva do negro no Brasil e no mundo), têm mais em comum com fervos promovidos por coletivos como o Fora do Eixo/Mídia Ninja do que se tem pensado até então. 
Considerei "politicamente engajadas" as festividades e os espaços que trazem no seu processo organizacional um profundo sentimento de articulação em rede com lutas e agendas sexuais, de gênero, raça, territorialidade e outras dimensões da vida social. Tais festas RE Clcontribuem, como nos propõe Amaral e outras autoras, com a mediação cultural e o 'TIL DC intuito de reconhecer tais festividades no âmbito da dinâmica de organização da vida social.

Entendemos, para fins analíticos, os conceitos de dimensão da vida social e geração nos termos propostos pela professora Alda Mota. Para ela, a vida social é estruturada em conjuntos de relações que, em interface, ou articuladas dinamicamente, lhe dão sentido (ou ensejam ao analista entrever um sentido). (MOTTA, 1999). Ela continua nos apontando que

\begin{abstract}
Os mais determinantes desses sistemas de relações são as classes sociais, os gêneros, as idades/gerações e as raças/etnias. Cada conjunto desses constitui-se, então, numa dimensão básica da vida social, mas nenhum deles, analisado isoladamente, dá conta da sua complexidade. [...] Essas dimensões realizam-se no cotidiano e na História e podem ser também definidas como categorias relacionais ou da experiência [...] o conhecimento de cada uma das categorias remete, sempre, a uma análise de relações de poder. (MOTTA, 1999: p. 193-194)
\end{abstract}

Embora a professora Alda Motta nos apresente classe, gênero, idade/geração e raça/etnia, sabemos que outras categorias relacionais ou da experiência são igualmente consideradas valiosas e determinantes para compreender as relações de poder no cotidiano presente e na História (MOTTA, 1999). Motta nos mostra que idade e geração precisam, no contexto da compreensão destas categorias como forma de estruturar a compreensão sobre a vida social, ser entendidas nas suas diferentes funções. Ela apresenta que

\footnotetext{
o tempo dos indivíduos é expresso mais perceptivelmente pela idade, mas, sabemos, é socialmente construído, e institucionaliza-se, isto é, adquire significado mais diretamente social como grupos de idade - jovens, adultos, velhos - ou como legitimidades para realizar, ou não, tal ou qual ação social. [...] A inseparabilidade e intercambialidade analítica das duas categorias de experiência [...] podem ser exemplificadas na asserção de Zárraga Moreno 'toda geração é determinada pela sucessão de conjunturas históricas em que vive, ainda que o efeito... de cada conjuntura seja distinto de acordo com a categoria de idade em que se encontra cada geração.' [...] Como geração, os indivíduos, inescapavelmente, se reconhecem, como projeção coletiva. (MOTTA, 1999: p. 205-206).
}

No mesmo sentido da professora, Alana Moraes e Jean Tible conceituam na publicação "Cartografias da Emergência: novas lutas no Brasil" (2015) um entendimento sobre o termo “geração política”. Para elas:

Pensar em termos de "geração política" nos parece interessante na medida em que esse conceito se abre para pensarmos também o conjunto de experiências políticas 
comuns que afeta e produz subjetividades em um determinado período: suas questões, fissuras, dilemas e rupturas. Não se trata, portanto, de um corte geracional no sentido etário (inclusive a idade dos entrevistados é variada), mas de pensar uma produção política a partir de uma experiência comum de embates, questões e desejos que se abrem em um determinado momento histórico. (MORAES; TIBLE, 2015: p. 16).

Ao entender, portanto, que geração ou geração política tratam, no âmbito desta formulação, da marcação de uma produção política a partir de uma experiência comum em um determinado momento histórico (MORAES; TIBLE, 2015), com contribuição para pensar o cotidiano e a História (MOTTA, 1999), nos propusemos a identificação de uma geração política fervida - ou simplesmente: uma geração fervida. Explico: para este autor é caro marcar que as organizadoras e participantes de determinadas festividades ou conjunto de deslocamentos utilizando figuras envolvidas nestas festas politicamente engajadas, nos apresentam contribuição suficiente para repensar pontos de partida para o nosso atual momento histórico. É disso que estamos falando: arte, cultura e política; classe, gênero, raça, sexualidade...

\section{A Frente Negra Brasileira, os Bailes e a Soul Music: a linhagem preta do fervo}

\footnotetext{
"Eu acho que esses movimentos não são movimentos isolados. Se você quiser historicamente ver a busca de uma identidade do negro num contexto universal a partir das suas experiências nas Américas e particularmente no Brasil [...] esse movimento Soul me parece um movimento de identidade racial através de uma identidade musical que é o Soul. Os negros não estão se identificando com o rock ou com qualquer outra forma, ou com a Balalaika ou com a Troika, eles estão se identificando com alguma coisa que lhes diz respeito."

Trecho transcrito da fala do sociólogo e militante negro Eduardo de Oliveira e Oliveira no documentário "O Negro da Senzala ao Soul”, TV Cultura (1977)
}

O trecho acima é de uma entrevista do professor e sociólogo negro Eduardo de Oliveira e Oliveira em 1977 para o documentário "O Negro da Senzala ao Soul” produzido e lançado pela TV Cultura de São Paulo naquela data. Chegamos até o documentário ao nos inscrevermos no curso online disponibilizado pela página da festa Batekoo denominado "Geração Tombamento: pressupostos históricos e paradigmas atuais". No documentário, Oliveira, assim como a historiadora negra Beatriz Nascimento, e outras intelectualidades e personalidades negras do futebol, da música ou da chamada Imprensa Negra Paulista da época, trazem diferentes leituras sobre as novas movimentações da chamada "4a geração de negros/as pós abolição" ocorrida em 1888.

Eduardo de Oliveira e Oliveira nos faz refletir sobre o papel que teve o movimento dos Bailes de Soul nos anos 1970 para a construção de uma identidade e consciência racial entre jovens negras/os. Elas e eles, passavam a (re)conhecer a si próprias(os) por meio dos encontros 
proporcionados por esse movimento de festas chamadas à época de Bailes Black ou Baile Charme. Com certeza em menor proporção do que outrora, mas não é incomum vermos ainda hoje o uso do termo Baile em composições de artistas negras/os (como BNegão e sua música R C El "Essa é pra tocar no Baile" [2012] que reivindica em sua composição o direito de festejar) ou

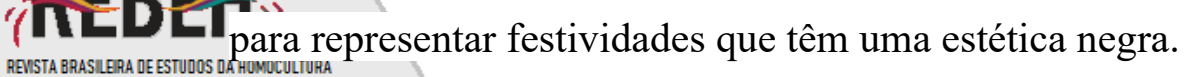

O Soul, estilo musical que dominava os Bailes nos anos 70 e disputava com o Samba (e mais pra frente com o chamado Samba Rock, sendo inspiração também para ritmos como o Afrobeat), era visto como um instrumento de libertação do negro americano e associado a uma imagem de negro livre pela geração de jovens de cor da época. Já na década de 30 a Frente Negra Brasileira realizava festas voltadas para a produção de uma sociabilidade da população negra de São Paulo. Os Bailes produzidos por grupos como Rosas Negras (de mulheres negras, que se vestiam de branco, usavam luvas negras e uma rosa pendurada no peito), Aristocratas Clube, Clube 220 e Coimbra são algumas das citadas no livro e documentário produzido pela organização Quilombhoje e lançado nos anos 2000 com apoio da Fundação Cultural Palmares com o título "Bailes - Soul, Samba Rock, Hip Hop e Identidade em São Paulo" - indicação que também colhemos do curso online da Geração Tombamento.

A Frente Negra Brasileira, como consta no site da Fundação Palmares ${ }^{4}$, era autodenominada "órgão político e social da raça". Ela foi fundada em 16 de setembro de 1931 em São Paulo e chegou a tornar-se um partido político com candidatura própria em 1937. Sua extinção acontece no mesmo ano a partir do ato de Getúlio Vargas que põe na ilegalidade todos os partidos políticos. Ao lermos os escritos do livro "Frente Negra Brasileira - depoimentos" o que percebemos é que boa parte das pessoas negras da época eram mobilizadas por ela. Dentre suas ações estava cuidar da parte recreativa e social das vidas de pessoas negras(os), que tinha relação direta com a organização de festividades, concursos e iniciativas que possibilitavam às pessoas negras se encontrar. Foram esses espaços de bailes, concursos, etc. que se tornaram também fundamentais para difusão dos posicionamentos políticos de uma geração de negras(os) por meio dos seus diferentes folhetins e jornais. Os Bailes eram os festejos mensais mais esperados. Conforme identificado no trecho de um dos depoimentos, a Frente cresceu muito e chegou a ter delegações no Rio de Janeiro, na Bahia, no Rio Grande do Sul, em Minas Gerais (RIBEIRO, BARBOSA, 2007) que se mobilizavam em caravanas para acompanhar algumas festas maiores.

\footnotetext{
${ }^{4}$ Página no site da Fundação Cultural Palmares em que fala da Frente Negra Brasileira está disponível no endereço http://www.palmares.gov.br/?p=2913 acessado em 09 de abril de 2019.
}

Vol. 02, N. 04, Out. - Dez., $2019 \cdot$ www.revistas.unilab.edu.br/index.php/rebeh 
Com uma sede própria, que funcionava no centro de São Paulo, a Frente mantinha uma -programação que buscava preparar o negro para o mercado de trabalho disponível naquela época. Ela também pensava no seu lazer e na sua sociabilidade, em um contexto recente de RE Clabolição da escravatura que jogou milhões de filhas(os) e netas(os) de pessoas sequestradas, 'TILC DLE traficadas e escravizadas a sua própria sorte. Não era pouco o papel que a Frente jogava contra RENSTA BRASILERA DE ESTUDOS DA HUMUCULIUHA

uma sociedade assumidamente racista, ainda escravista e que de maneira declarada discriminava pessoas negras em anúncios de seleção de empregos, acesso a Clubes e estabelecimentos comerciais, dentre outras barbáries que seguem ocorrendo ainda hoje, mais de 130 anos depois, sob novas roupagens e formas. A Frente era a grande responsável na época por reconhecer as diferentes expressões do racismo no Brasil e de denunciá-lo nacional e internacionalmente.

Ainda nesse período, entre os anos de 1924 e 1935, existiu no Brasil a chamada Imprensa Negra, sobretudo em São Paulo. Ela tinha em “O Clarim da Alvorada”, jornal lançado por José Correia Leite e Jayme de Aguiar, um elemento fundamental na construção de uma consciência política e social no meio negro. Sua distribuição acontecia nos já tradicionais bailes negros, pois para Leite e Aguiar essas agremiações dançantes tinham papel fundamental na "condução dos jovens negros que vêm crescendo sem acompanhar a evolução grandiosa do Brasil de hoje". Registra-se que em suas primeiras edições o foco era mais literário, mas a partir de 1928 ele ganha uma conotação política fundamental na denúncia do racismo e do fortalecimento de uma consciência negra:

Foi durante sua segunda fase, de 1928 a 1932, que O Clarim d'Alvorada conquistou prestígio entre os/as negros/as letrados/as. Os textos passam a ser politizados, denunciam o racismo fundante da sociedade brasileira, reivindicam direitos e defendem incansavelmente a união necessária da gente preta. (GONÇALVES, 2015: retirado da internet).

Chegamos às décadas de 40 e 50, período em que as escolas de samba deixam de ser reprimidas pela polícia e o rádio passa a divulgar a música feita nos morros e terreiros: o samba. Considerados como maiores especialidades da expressão física do negro, samba e futebol terminam sendo dois caminhos de possível ascensão para as pessoas negras - segundo a narrativa apresentada no documentário “O Negro da Senzala ao Soul”. Ele traz uma narrativa que ironiza as duas atividades em que o negro usando apenas o corpo mostra inegável talento, fazendo parecer que a discriminação cede um pouco, afinal trata-se de usar o corpo e não a cabeça.

Vol. 02, N. 04, Out. - Dez., $2019 \cdot$ www.revistas.unilab.edu.br/index.php/rebeh 
Diferentes gerações de jovens negras/os e de periferia identificavam na participação nos bailes dos anos 70 uma forma de valorizar a estética, a cultura e identidade negra elementos identificados como determinantes na organização de festividades como a Batekoo, RE ClAfrobapho e TOMBO, que foram estudadas na Defesa do Fervo (SILVA, 2018). Eles se '슨 tornaram um importante espaço de reconstrução da autoestima a partir da positivação do negro que não era representado na televisão ou nos filmes brasileiros da época, muito menos nas referências acadêmicas, sociais ou políticas.

A imagem negativa sobre o continente africano começa a ser combatida por uma geração que busca se afirmar por meio do uso de roupas, cumprimentos e estilos de música de identificação negra. Como vimos no documentário da TV Cultura de 1977, o negro norteamericano neste contexto é apresentado como uma imagem de "negro livre", de modelo de ascensão e liberdade. O impedimento da construção de uma identidade positiva do negro é denunciada como uma operação deliberada do pós abolição, como forma de estruturar um dos pilares fundamentais de sustentação do racismo brasileiro. Ao questionar a ausência de artistas, produtoras/es, performers e elementos que positivem a estética negra no lugar de estigmatizála, o fervo parece caminhar por um sentimento bem aproximado daquelas gerações negras dos anos 70-80.

Vimos ainda no documentário "O Negro da Senzala ao Soul" (1977) alguns depoimentos de participantes dos bailes. Um deles afirmou

\begin{abstract}
O Soul como ponto de partida, como cultura, se conscientizar, ser uma massa consciente. O negro consciente de si. [Por que o Soul?] O Soul também é de origem negra. Eu tive isso como ponto de partida de África. Como que foi diversos nativos para Estados Unidos, Inglaterra, Brasil. Então é um ponto de partida. Aqui também tiveram cantores de Soul como Cassiano, Carlos da Fé [mais tarde Carlos DaFé]. É um ponto de partida de África. [...] A gente acha que é coisa da gente também. A gente dá valor porque é um trabalho negro. (Trecho retirado da declaração de Nelson, identificado como trabalhador da Rede Tupi, no documentário "O Negro da Senzala ao Soul", TV Cultura, São Paulo, 1977, a partir de 36'10'”).
\end{abstract}

Chegando a mobilizar 1 milhão e meio de jovens a cada fim de semana no Rio de Janeiro, os Bailes de Soul passaram a ser objeto de atenção e assustar a indústria musical. Normalmente os bailes eram organizados pelas chamadas "Equipes", que cuidavam de toda parte de produção. Como é trazido no documentário "O Negro da Senzala ao Soul”, quando uma Equipe dava um Bailes as outras iam como público demonstrando uma forma de fortalecer um circuito dessas festividades e uma rede de afetividades entre pessoas e produções negras. Enxergamos uma relação de afeto similar no comportamento de organizadores(as) da Batekoo, Tombo e Afrobapho, onde as "Equipes" estavam para o contexto dos bailes dos anos 70 como os “Coletivos" estão para o contexto dos circuitos fervidos que acompanhei a partir de 2015.

Vol. 02, N. 04, Out. - Dez., $2019 \cdot$ www.revistas.unilab.edu.br/index.php/rebeh 
Da mesma forma cabe salientar o fortalecimento dessas festas como um circuito integrado e articulado de jovens negras(os), mulheres e LGBT de periferia que buscam enfrentar um conjunto de desigualdades sociais que as(os) afetam, tomando como partida questões raciais, RE CIsexuais, de classe e gênero.

A Soul Music era considerada uma música que "empurra pra frente". Na interpretação de Eduardo de Oliveira e Oliveira na época se as(os) negras(os) estavam deixando de ouvir samba e passando a ouvir Soul, era necessário ouvir os motivos apresentados por essas pessoas para tal mudança. Fazendo referência a declaração de pessoas negras sobre o Soul em uma reportagem da Revista Veja, Oliveira e Oliveira diz que "Na reportagem de Veja, os rapazes dizem que eles aderiram ao Soul porque é uma música que empurra pra frente, então eu me pergunto: o samba que está sendo feito no Brasil empurra pra frente?". Um outro elemento apresentado no mesmo documentário para tal migração do samba para o Soul é a entrada da classe média nas escolas de samba, o que fez, segundo os depoimentos apresentados no documentário supracitado de 1977, com que "o negro se sentisse expulso de lá".

O Soul ainda é apresentado como uma época em que a juventude negra resolveu "dançar uma música diferente". Eduardo de Oliveira e Oliveira no referido documentário diz o seguinte:

\begin{abstract}
Eu acho que esses movimentos não são movimentos isolados. Se você quiser historicamente ver a busca de uma identidade do negro num contexto universal a partir das suas experiências nas Américas e particularmente no Brasil [...] na pinacoteca do estado, atualmente na exposição "A imprensa negra de São Paulo", você pode ver a importância que teve para os movimentos sociais e políticos de São Paulo o movimento do Marcus Garvey, nos Estados Unidos na década de 20. Também depois você pode ainda ver através dos jornais toda a importância que teve a guerra da Abissínia, e a identificação que os negros se identificavam com a problemática africana naquela época. Agora esse movimento Soul me parece um movimento de identidade racial através de uma identidade musical que é o Soul. Os negros não estão se identificando com o rock ou com qualquer outra forma, ou com a Balalaika ou com a Troika, eles estão se identificando com alguma coisa que lhes diz respeito." (Trecho transcrito da fala do sociólogo e militante negro Eduardo de Oliveira e Oliveira no documentário "O Negro da Senzala ao Soul” produzido pela TV Cultura, São Paulo, 1977, a partir de 39'41'”).
\end{abstract}

O Soul era visto como um instrumento de representação da imagem do "negro livre americano". A disputa por esse imaginário e essa consciência racial era operada também na época por um conjunto de intervenções das intelectuais negras(os) que ao adentrar as Universidades passam a problematizá-la no que diz respeito ao sentido prático da produção do conhecimento. Na época em que o documentário foi gravado, 1977, organizava-se no país a "Quinzena do Negro". O objetivo, o foco e o saldo político dela, nas palavras de Oliveira e Oliveira (um dos organizadores), foram os seguintes: 
[...] o objetivo primordial foi trazer o negro para o centro de interesse e preocupações, mesmo que por 15 dias, [...] para que ele deixasse de ser invisível, [...] para ser apresentado como homem, como criatura e criador. [...] Trazer para o conhecimento público o que se está fazendo no Brasil ou fora do Brasil em torno de ciências sociais com relação a problemática racial. [...] Acabar com uma certa balcanização que se existe no conhecimento, quer dizer, o que se faz no Rio não se conhece aqui, o que se faz aqui não se conhece lá, muito menos na Bahia, muito menos em Belo Horizonte.[...] Reunir um grupo de cientistas sociais negros que estão trabalhando na área e são voltados especialmente para isto, com uma dupla finalidade: mostrar o que eles estão fazendo; e segundo também apresentá-los numa projeção positiva para o novo grupo de jovens que estão surgindo e que precisam ver negros em papéis que geralmente não lhe são atribuídos. [...] As pesquisas são feitas, mas sem pensar que essa pesquisa deve ser voltada para a experiência do negro atual, para os seus problemas atuais, que ela tenha um cunho prático de servir ao negro. Geralmente serve mais ao cientista. [...] [A "Quinzena do Negro"] Veio provar a necessidade de se fazer um trabalho para, a quantidade de gente que apareceu, e sobretudo a quantidade de gente negra interessada, revela que esse grupo está precisando que se pense nele, e se o estude, e se façam trabalhos que incidam diante das suas problemas atuais, que não são conhecidas, nem pensadas. (Trecho transcrito da fala do sociólogo e militante negro Eduardo de Oliveira e Oliveira no documentário "O Negro da Senzala ao Soul" produzido pela TV Cultura, São Paulo, 1977, a partir de 01'15"').

A música soul e os bailes são uma importante base histórica para entender parte das raízes negras do fervo. Assistimos documentários, pesquisamos sites e resgatamos documentos on-line que nos ajudaram a compor elementos históricos capazes de circunscrever referências mais raciais e assim compreender as expressões de festividades produzidas por um conjunto de jovens negras(os), mulheres e LGBT, de periferia em Salvador no ano de 2016 de maneira mais nítida. Vimos, ainda, essa cena fervida se desenvolver desde então e a partir de discussões que intereseccionavam dimensões raciais, sexuais, de classe e gênero como um novo ponto de partida fundamental.

Há muito mais em comum entre os bailes e o fervo do que se tem apostado até então. Afirmamos isso pois, mesmo com todas as diferenças ideológicas que são apontadas em relação às posturas da Frente Negra Brasileira (que era acusada de flertar com a monarquia e o integralismo da época), é fato que ela enquanto organização política negra reconhecia e promovia os bailes como forma de integrar a sua base social e organizá-la para disputar todos os setores da vida brasileira. Essa característica de utilizar as festividades dos bailes como forma de organização e participação das(os) negras(os), sem dúvidas, influenciou toda uma geração pós abolição ou suas filhas e seus filhos que cresceram nos anos 1930 e que por sua vez também influenciaram e formaram as(os) que vieram depois delas.

Tal influência parece ter ganhado força novamente, após as experiências em 1930 com a Frente Negra e chegado nos anos 1970 por meio dos bailes, que ocupavam os centros urbanos do país mobilizando muita gente jovem, preta e de periferia. A Soul Music, pela conexão que ela tinha com o ideal de valorização do negro livre, conduzia a noite, mas outros ritmos foram 
também ali experimentados e criados. Aposta-se que foram essas cenas de bailes de 1970 que deram as bases da construção do rap, do hip hop, do funk, do afrobeat, do sambareggae e outras expressões musicais, que talvez não tão a toa assim sejam parte do que se ouve na pista de RE Cl festividades como a Batekoo e Afrobapho ao lado do pop nacional e internacional. Segue o '( 11: D baile!

\section{Do fervo ao gueto: a linhagem da contracultura-tropicalista}

enquanto os homens exercem seus podres poderes Índios e padres e bichas, negros e mulheres e adolescentes fazem o carnaval

Podres Poderes - Caetano Veloso (1984)

O fervo, para nós, reflete elementos históricos de uso dos espaços de sociabilidade, proporcionados sobretudo pelas festas urbanas, como forma de contestar a ordem social ou organizar o reconhecimento de pertenças identitárias. Como vimos com Amaral (1998) o uso das festas com essa conotação já era notado de longa data. A contracultura, internacionalmente, e o tropicalismo (1960-1970), localmente, ajudaram a conectar uma geração com ideais e pautas de contestação social ao regime civil-militar da época.

No mesmo sentido, o gueto macraeano serviu para dar contornos mais nítidos à ideia de identidade homossexual no Brasil (1970-1980) neste mesmo período - onde acontecia, ainda, como vimos no tópico anterior, a emergência do circuito dos bailes de Soul (1970). Se os bailes foram decisivos na consolidação de uma consciência e identidade negra, por meio da valorização da cultura, da música, da linguagem e da estética, nos anos 1970; o gueto teve sentido similar, mas com a função de afirmar a identidade de pessoas que passavam a se identificar social e politicamente como homossexuais. Contudo, por que a contracultura influenciou mais o gueto do que os bailes de soul? É o que veremos neste ponto do artigo.

O uso dos espaços de sociabilidade proporcionados pelas festas como forma de contestar a ordem social marcou a contracultura na história ocidental por seu caráter libertário. O uso de drogas como contracultura, assim como ela própria, encontrou na música uma forma e um método fundamental, alcançando nos anos 1960 uma juventude de camadas médias urbanas, sobretudo universitária (PEREIRA, 1980, p. 5/37). O que era considerado "lixo" pelos padrões intelectuais da ordem social vigentes da época era elevado por esse movimento à condição de matéria-prima para suas criações.

Vol. 02, N. 04, Out. - Dez., $2019 \cdot$ www.revistas.unilab.edu.br/index.php/rebeh 
Os ideais do movimento da contracultura referenciavam uma postura radicalmente alternativa. Ela era propagada e acessada por uma juventude universitária, reconhecida por diversos privilégios sobretudo raciais (em sua maioria brancos/as) e de classe (médias e altas).

RC CIMisturando música e comportamento como expressões de um descontentamento social, a

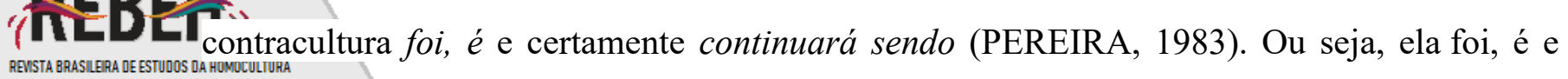
poderá continuar sendo, se servir para conectar pessoas e mobilizá-las em torno de uma perspectiva crítica e libertadora.

Um dos seus principais pensadores brasileiros - Luiz Carlos Maciel - apresenta em anotações da época a existência de duas possibilidades para compreender a contracultura, considerando ela (a) como fenômeno histórico localizado dos anos 1960, demarcando a ideia de que a contracultura não é, só foi; e (b) como uma postura, uma posição, em face da cultura convencional, de crítica radical.

Maciel é o autor do livro Geração em Transe - memórias do tempo do tropicalismo. Nesse, ele constrói um registro importante sobre as contribuições que figuras como Caetano Velosos e Gilberto Gil (na música), Glauber Rocha e Ubaldo Ribeiro (no cinema e literatura) e José Celso (no teatro Oficina) tiveram para consolidar o que ele caracteriza como uma Rebeldia Existencial (MACIEL, 1996: p. 23) e Rebeldia Política (MACIEL, 1996: p.31). Para ele, a rebeldia existencial conectava a Geração em Transe com as ideias existencialistas de Simone de Beauvouir e de Sartre. A rebeldia política, assim como o existencialismo, aproximavam esta geração em transe das ideias de esquerda, como a revolução cubana e a luta contra o capitalismo global.

Uma expressão brasileira da contracultura ganhou contorno, sobretudo, a partir da movimentação em torno do tropicalismo. Rafael Noleto (2014) vai nos contar em seus estudos como o Tropicalismo atingia um público de jovens brasileiros interessados em discutir política, sexualidade e liberdade de expressão (NOLETO, 2014, p. 64). Embora seu estudo faça referência a performance da cantora Gal Costa e as contribuições dessa expoente feminina a esta movimentação cultural, nas suas conclusões ele nos sugere que cada um dos seus membros teve uma contribuição específica na construção do movimento (NOLETO, 2014, p. 73). Neste sentido, ao buscar as influências que a contracultura-tropicalista teve no gueto pensamos elas a partir das compreensões apresentadas por Maciel, Noleto e MacRae. Esse último (quem formulou a defesa do gueto) vai nos trazer o gueto como o local de encontro tanto da rebeldia existencial e política quanto do que Noleto irá nos apresentar como a ideologia do desbunde. Ao juntarmos os estudos de Noleto (2014) sobre Gal Costa e MacRae (1983) sobre o gueto 
conseguimos fundamentos do período de 1960 e 1970 que nos permitem sugerir a linhagem da contracultura-tropicalista como uma das influências do fervo.

Isso porque, dentre outros elementos, Noleto contribui e muito para conceituar a ideia R. $\mathbf{C l}$ do desbunde. Apresentada nas formulações macraenas, ele é um termo que representa mais as '슨둔.

existiam naquele período. O desbunde para Rafael Noleto atuou como uma ideologia, sendo que:

Esta expressão [ideologia do desbunde] possui origem na postura política (e não estética) assumida por determinados grupos de jovens da época, como bem definiu Daniel Gonçalves: 'A concepção de arte engajada, predominante nos anos 1960, conheceu sua resistência por meio da revolução comportamental, que se difundiu mundo afora, e da instituição da ditadura militar, que fez com que fossem varridos os anseios de transformação da sociedade brasileira. Ambos os aspectos provocaram a revisão e o questionamento dos preceitos fundamentais da prática política tradicional. Ideologia do desbunde - Para a ala engajada, esse movimento de rejeição do modelo de contestação política tradicional era conhecido como desbunde, designação dada àqueles que deixavam a militância política em favor de projetos pessoais. MAis especificamente, talvez possamos pensar em termos de gerações, afirmando que parte dos integrantes da geração dos anos 1970 - o que não exclui integrantes de outras gerações -, não reconheciam mais na militância política um ideal de vida a ser seguido e, em convergência com a liberdade proposta pelos movimentos de contracultura, adotaram o desbunde como signo de rebeldia e descrença em relação aos projetos revolucionários e, de certo modo, também à ordem vigente' (GONÇALVES, 2008, p.31)"' (NOLETO, 2014, p. 75, nota de rodapé 6).

Ao olhar para as diferentes movimentações culturais protagonizadas hoje por jovens fervidas é possível dizer que a contracultura não é, só foi? Ou, ainda, podemos dizer que sua ideia de crítica radical proposta por Maciel estaria na capacidade de significar a realidade social ou o que é colocado à sua margem sobre novos marcos, parâmetros e referências históricas, sendo assim uma postura, posição, viável ainda hoje? Bebemos nessas duas perspectivas de Maciel para pensar a herança trazida dessa linhagem nos contornos que temos dado ao fervo. Mas também nos arriscamos aqui a propor um terceiro entendimento.

Refletimos que a entrada de artistas como Caetano Veloso no circuito mainstream da indústria da música brasileira e internacional pode ser, hoje, vista como positiva para que a contracultura-tropicalista não pare no foi e continue sendo. Embora ele participe de circuitos que comumente reproduzem a cultura considerada convencional, vê-lo investir na diáspora de artistas negras baianas (como vimos em 2019 a partir das experiências construídas junto a Casa Ninja Bahia), da cena do rap baiano, como Majur (pessoa não-binária) e Hiran (gay, da cidade de Alagoinhas, interior do estado), representa, para nós, um gesto importante nos dois sentidos propostos por Maciel e na compreensão diaspórica feita por um grupo de cantores(as) baianos(as). 
Noleto nos sugere que a disputa da indústria musical a nível local e global, já parecia ser um dos objetivos da movimentação Tropicalista daquela época. Ele afirma que a concepção inicial do Tropicalismo que artistas como Caetano Veloso e Gilberto Gil defendiam, passava RE CIpor fazer com que a música brasileira dialogasse com a produção musical internacional,

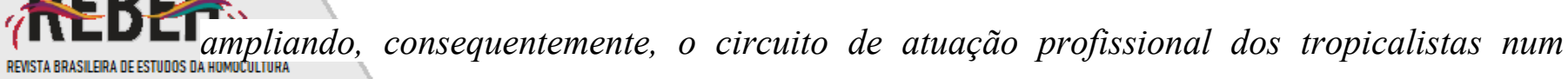
contexto mundial (NOLETO, 2014, p. 68). E nos dá espaço com isso para supor que o movimento proposto por Caetano hoje a artistas como Majur e Hiran se assemelham aos caminhos diaspóricos percorridos por artistas como ele, Gal Costa, Maria Bethânia, Tom Zé e Gilberto Gil, ao saírem do nordeste para o sudeste brasileiro em um primeiro momento, visando ocupar o eixo Rio-São Paulo com uma novidade cultural por meio de uma movimentação musical e levando consigo uma série de marcações e contornos existenciais importantes.

Por um lado, podemos identificar que ele, um expoente da contracultura-tropicalista dos anos 1970, pode cumprir um outro papel hoje - de mediação importante junto a indústria musical brasileira e internacional. Por outro lado, essa postura o aproxima de um conjunto de pessoas, identificadas sobremaneira com uma crítica radical a cultura convencional nos marcos e condições que ela se apresenta hoje, que podem ter aí uma oportunidade de visibilizar suas produções e com elas as narrativas coletivas de uma geração. Além disso, esses fatos em si, materializam uma experiência empírica que coloca em diálogo protagonistas da contraculturatropicalista (como Caetano) e herdeiras dos bailes (como Majur e Hiran). Como fazer com que esse potente encontro não seja um mero acordo comercial, nem se perca nos prováveis embates e contradições que qualquer relação está sujeita a recair? Como fazer dessa possibilidade uma inflexão histórica para o acúmulo de um novo paradigma existencial no campo das movimentações culturais brasileiras?

Foi refletindo sobre e experimentando etnograficamente essa aproximação possível que resolvi apresentar a ideia de uma geração fervida, como uma possível conectora de herdeiras da contracultura-tropicalista e dos bailes de soul (rap, hiphop, etc), pois identificamos que essa possibilidade já tem mostrado potência existencial e reflexiva, mesmo sem se compreender como uma operação que pode (e, talvez, deva) caminhar mais junta e de maneira ainda mais coordenada. Para além de um nome, tal qual o Tropicalismo o foi no passado, é necessário um locus, um campo, algo onde esses pontos de partida se encontrem em uma relação que seja diferente da oferecida pela mera operação do grande capital - representado aqui na aproximação dessas novas artistas dos circuitos da indústria musical que Caetano acessa.

Ainda é preciso contextualizar que a contracultura se desenvolve em um momento de surgimento do rock mundial (anos 50) e de intensas mudanças culturais no Brasil. Nos anos de Vol. 02, N. 04, Out. - Dez., 2019 · www.revistas.unilab.edu.br/index.php/rebeh 
1950 experimentamos um período considerado rico, intenso e aberto à participação popular (MARTINS, 2015: p. 414/416) no país. Foi um momento de intenso florescimento artístico, industrialização, urbanização e migração com a construção de estradas que passaram a RE CIpromover a integração nacional (MARTINS, 2015: p.414). O estudo de Franklin Martins '(TILCLCT dènominado Quem foi que inventou o Brasil? - A música popular conta a história da República (2015) mostra como entre 1954 e 1964 foram vividos os chamados "anos dourados" de democracia e de liberdade despertando o país para suas potencialidades e seus problemas (MARTINS, 2015: p. 414).

Dourados, mas nem tanto uma vez que foram inúmeros os ataques e tentativas de golpe operadas neste período por altos chefes militares, articulados com lideranças civis avessas à democracia, entre às quais se destacavam a UDN e um dos seus principais líderes, Carlos Lacerda. (MARTINS, 2015: p. 416). Uma das primeiras tentativas de golpe foi a que tentou depor o presidente Getúlio Vargas e o levou ao suicídio justamente no ano de 1954. Entender este período e o desenvolvimento da contracultura nele têm uma importância peculiar para compreender o fervo hoje. Como nos apresenta Martins, existia uma divisão nítida na sociedade:

\footnotetext{
De um lado, o aumento progressivo da participação política dos trabalhadores e do povo, que estimulados pelo ambiente democrático, passaram a identificar e defender seus interesses. De outro, a dificuldade crescente dos setores conservadores em aceitar e acatar às regras democráticas, que favoreciam a irrupção das demandas sociais antes reprimidas. (MARTINS, 2015: p. 416-417).
}

Tal cenário apresentado por Franklin Martins retrata um período entre anos 1950 e início dos anos 1960, que é encerrado com o golpe civil-militar de 1964. Resguardados os limites e desfechos diferenciados pelo atual momento, as palavras de Martins poderiam muito bem descrever o contexto de golpe de 2016. E enquanto lá terminou sendo um ambiente fértil para o surgimento da contracultura e do próprio tropicalismo (assim como de outras movimentações), que fundamentaram a ideia de uma geração em transe (MACIEL, 1996), acreditamos que a edição contemporânea do golpe (2016) e a própria eleição da Nova Era fascista em 2018 pode ser fértil ao levante e constituição de uma nova geração política que consiga ser atrativa a jovens negras(os) e da periferia, que defendem sobretudo o direito a estarem vivas; mas que também se encontram em algum momento com as jovens das classes médias e altas, e que defendem juntes os direitos das pessoas LGBT, que enfrentam a violência contra as mulheres e a cultura do estupro, que pensam e vivem em seus ambientes uma outra relação com o uso de drogas e fazem do fervo uma celebração da vida, mas também uma forma de nos encontrarmos para tramar a nossa rebeldia existencial e política mais atual. 
Apresentaremos no tópico final a defesa e os elementos que acreditamos serem fundamentos e desafios para se pensar uma Geração Fervida hoje.

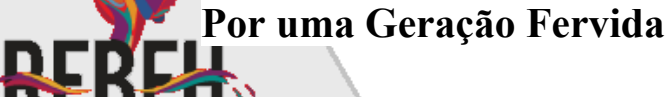

O gueto seria o circuito que colaborou para a construção e reconhecimento do sujeito homossexual no início da década de 1980. É o gueto que possibilita a legitimação desta nova identidade social perante a sociedade, que também se deparava com as performances de Caetano e dos Dzi Croquettes, de maneira mais aberta e pública, como um afronte a ordem hegemonicamente estabelecida e rígida sobre o sexo e a sexualidade.

É no gueto onde, por um lado, diferentes sentimentos de culpa, medo e ostracismo foram momentaneamente afastados e onde o homossexual tinha mais condição de reconhecer e assumir sua nova identidade. Por outro, é a partir dele e das condições por ele criadas para que estas pessoas expressassem seus estilos de vida e comportamentos que outras áreas da sociedade passaram a ser afetadas (MACRAE, 1983). Como colocado por Júlio Simões e Isadora França, o "gueto" era algo que só poderia ser entendido e delimitado a partir do acompanhamento dos deslocamentos dessas pessoas homossexuais através dos lugares em que exercem atividades relacionadas à orientação e à prática homossexual (SIMÕES; FRANÇA, 2005, p.310-311).

O gueto remete, portanto, a um circuito de contestação homossexual em um período intenso de transformações sociais que aconteciam no país, fruto, sobretudo, do enfrentamento ao regime civil-militar iniciado em 1964. Havia um endurecimento nas ações repressivas e autoritárias da ditadura civil-militar, na perseguição e punição dos desviantes à moral e aos bons costumes - qualquer semelhança com os atuais tempos do Brasil, não é mera coincidência. Contudo, organizava-se também uma ampla e diversa resistência, que passou a ser assumida de diferentes formas e maneiras a partir de espaços públicos e privados.

$\mathrm{O}$ fervo representa para nós uma experiência que tangencia a história do gueto. $\mathrm{O}$ primeiro, identificado no presente, assim como o segundo, identificado no passado, ocupa um lugar de contestação social, afirmação política e experiências de reconhecimento pluriidentitário. Operado sobretudo por uma geração política, que algumas se esforçam para denominar de tombamento, mas que vi em entrevistas com interlocutores como Alan Bispo, idealizador do do Coletivo Afrobpaho, ou Gabriel Oliveira, que foi fotógrafo da primeira Vol. 02, N. 04, Out. - Dez., $2019 \cdot$ www.revistas.unilab.edu.br/index.php/rebeh 
edição da festa Afrobapho (2016), que por diferentes motivos eles não se reconheciam aí. Por outro lado, o fervo não lhes parecia um termo que lhe causava a imediata conexão, mas também não representava uma imediata repulsa. Milla Carol, uma das produtoras da Batekoo naquele RCE CIperíodo, nos pareceu muito honesta ao responder em entrevista sobre o que era o fervo para '슨 rensta bras ILeRa de estudos da humuculium

Ora, caras leitoras, que tiveram a paciência de chegar até aqui, o que temos quando juntamos as pontas? Partirei do final para o início, tentando dar conta de sintetizar nesta conclusão a ideia em torno da geração fervida, que arrisco aqui ser uma convocação de pares necessária de ser feita neste momento para acumular forças contra a Nova Era fascista. O que nós estamos, na real, nos propondo a fazer é construir novas economias, novas filosofias, novos pontos de partida para uma forma de organizar a vida, ou, nos termos da professora Beatriz do Nascimento, acumular uma nova centralidade de poder - paralelo a tudo que aí está institucionalmente estruturado para nos oprimir e/ou nos controlar.

O fervo é o que nos organiza, porque seja o processo de organização da sua produção ou de organização da sua participação implicam na produção de micro-convivências e trocas. Elas acontecem entre um conjunto de pessoas das mais diferentes idades, bairros, condições sociais, raças, gêneros e sexualidades, mas que topam se encontrar em um local para elas "representativo" e interseccionalmente subversivo, no sentido de propor um novo marco de partida a partir de uma perspectiva interseccional e crítica da realidade social. Nele o protagonismo geracionalmente compartilhado é o que joga mais tinta sim nas pessoas cujas trajetórias de vida estão recortadas por processos de desigualdade racial, etário, de classe, gênero, sexualidade e outras dimensões da vida social. A Geração Fervida é o que nos aproxima da disputa real de um novo marco civilizatório - como propõe Érica Malunguinho e outras porque nos propõe, a sua maneira, uma outra filosofia e experiência para o que concebemos ser a própria humanidade e a vida. É disso que estamos falando!

A compreensão da festa como forma de contestação social foi utilizada em muitos momentos da história. A ideia de tornar geracionalmente possível a aproximação de setores em torno de uma geração fervida, que se organiza a partir desta compreensão articulada entre festa e contestação social, me parece estratégico para aglutinar setores que hoje estão dispostos, mas seguem dispersos, diminuindo assim o nosso potencial de incidência na determinação das relações de poder.

Para o pesquisador australiano Kane Race, uma festa é um evento: uma reunião provisória e temporária de diversos elementos, pessoas e coisas. Um modo festivo de participação social. (RACE, 2011, tradução nossa). Sem querer finalizar ou determinar os Vol. 02, N. 04, Out. - Dez., 2019 · www.revistas.unilab.edu.br/index.php/rebeh 
caminhos do fervo, buscamos aqui referenciá-lo historicamente como um circuito que transita por esse lugar, possibilitando por um lado a reunião provisória de setores que se identificam com as diferentes agendas de lutas sociais e políticas que essas festas, engajadas, defendem RE Clcomo ponto de partida ético e filosófico de suas organizadoras e de boa parte de suas

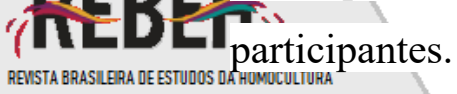

As sujeitas que proponho aqui serem entendidas a partir da ideia de geração política fervida têm sido determinantes para acumular em torno de uma outra cultura de participação social. Isso é perceptível quando vemos a força da solidariedade desta geração viabilizar a representação do coletivo Afrobapho em uma conferência contra homofobia na Jamaica no ano de 2019. Também percebemos isso quando vemos a repercussão dada a presença da Batekoo no festival Afropunk em Nova York (Agosto de 2019). Ou mesmo quando acompanhamos a força da colaboração para construir uma programação de referência junto a Casa Ninja Bahia, entre Janeiro e Março de 2019, na cidade de Salvador - com um grande protagonismo de artistas negras(os) e da periferia da cidade, que sentiram a valorização de suas produções ao ocuparem um casarão no Porto da Barra (área comumente frequentada e de moradia de classes médias ou altas da cidade de Salvador).

Como um coletivo como o Afrobapho, organizador de uma festividade, foi a representação política de LGBT brasileiras em uma conferência de combate a homofobia na Jamaica e não uma tradicional organização do movimento LGBT ou negro LGBT? Como conseguiu chegar lá sem apoio de agências internacionais ou de governos locais? Quem aglutina a conta positiva dessa solidariedade que nos parece estar dispersa embora ativa e se movimentando? Propomos aqui a ideia de geração fervida como este locus.

É na construção e participação ou mesmo no tangenciamento junto a produção de diferentes artistas e festividades que percebemos uma potente possibilidade para fazer com que setores diametralmente diferentes ou divergentes convivam, conversem, tramem o outro mundo possível. A nossa diversidade cultural, racial, de classe, gênero e sexualidade demandam esses encontram para que sigam se conhecendo e se atualizando, e grafando novos e respeitosos pontos da relação estabelecida entre si e com o mundo.

O que chamamos até aqui de geração fervida contribui no sentido da construção de um novo ponto de partida para pensar a organização da vida social por meio de uma perspectiva interseccional, que convoca a arte, a cultura, a comunicação e a política para o centro do engajamento social. Ou, ainda, em outras palavras, a geração fervida nos apresenta como o nosso rolê tem contribuído para compor o horizonte do novo mundo que a esquerda tanto fala 
em plenárias, frentes, fóruns, congressos, conferências e encontros; ou mesmo para juntar as pessoas necessárias à resistência proposta pelos movimentos sociais mais tradicionais.

Chegou a hora de mostrar à Nova Era, e a sua operação de reificação das estruturas RE Cldesiguais e coloniais, a força do nosso grito por cidadania, a emergência do nosso levante, por '(TIL DE Trespeito, dignidade e, sobretudo, por nossas vidas e humanidades. E nenhuma de nós fará isso sozinha. A nossa revolta geracional neste momento é em prol de um reposicionamento necessário para que a gente não acabe perdendo o que já conquistou. Para um novo momento histórico, novos erros, por favor! Fervidas do mundo, não percamos tempo, aquilombai-vos. Vem com a gente, que a luta continua... distraídas, venceremos!

\section{Referências}

AMARAL, Rita de Cássia de Mello Peixoto. Festas à brasileira: significados do festejar, no país que "não é sério". Universidade de São Paulo. São Paulo. 1998. Disponível em $<$ https://www.teses.usp.br/teses/disponiveis/8/8134/tde-21102004-

134208/publico/tesecapa1.pdf $>$ Acesso em 05 de julho de 2019.

MACIEL, Luiz Carlos. Geração em transe: memórias do tempo do tropicalismo. Rio de Janeiro. Nova Fronteira. 1996.

MACRAE, Edward. Em Defesa do Gueto. In; Novos Estudos CEBRAP. Vol. 2, nº 1, abril de 1983. pp. 53-60.

MARTINS, Franklin. Quem foi que inventou o Brasil? - Volume I. Rio de Janeiro. Nova Fronteira. 2015.

MORAS, Alana; TIBLE, Jean. Quando novos personagens entram em cena? In: MORAES, Alana; TARIN, Bruno; TIBLE, Jean (Org). São Paulo. Fundação Friedrich Ebert Stiftung (FES). 2015. p. 14-39.

NASCIMENTO, Beatriz. O conceito de quilombo e a resistência cultural negra. 1985. In: RATTS, Alex. Eu sou atlântica sobre a trajetória de vida de Beatriz Nascimento. São Paulo. Imprensa Oficial. 2006.

NOLETO, Rafael da Silva. "Eu sou uma fruta 'gogóia', eu sou uma moça": Gal Costa e o Tropicalismo no feminino. Per musi [online]. 2014, n.30, pp.64-75. Disponível em: http://www.scielo.br/scielo.php?script=sci_abstract\&pid=S1517-

$75992014000200009 \& \operatorname{lng}=$ en\&nrm=iso\&tlng=pt Acesso em 3 fevereiro de 2020.

PEREIRA, Carlos Alberto M.. O que é contracultura?. São Paulo. Brasiliense. 1983.

PEREZ, Léa Freitas.. Dionísio nos trópicos: festa religiosa e barroquização do mundo - por uma antropologia das efervescências coletivas. In: Mauro Passos. (Org.). A festa na vida: significado e imagens. 1ed. Petrópolis. Vozes. 2002. p. 15-58.

RACE, Kane. Party Animals: The significance of drug practices in the materialization of urban gay identity. In: S. Fraser \& D. Moore (eds.) The Drug Effect: Health, Crime \& Society. Cambridge University Press. Melbourne. Cambridge University Press. 2011. 
RIBEIRO, Esmeralda; BARBOSA, Marcio (Orgs.). Frente Negra Brasileira - depoimentos. São Paulo. Quilombhoje. 2007.

SILVA, Ariel Lucas; MIGUEZ, Paulo. Cultura, Festa e Cidade: tecendo relações. In: Revist@ Observatório da Diversidade Cultural, Vol. 1, n 1 . Belo Horizonte. 2014. Disponível em < RE Cllittp://www.observatoriodadiversidade.org.br/revista/edicao_001/Revista-ODC-001-02.pdf $>$.

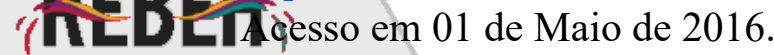

SILVA, Vinícius Alves da. Em defesa do fervo: olhares etnográficos sobre a produção de cuidado no contexto de festas urbanas em Salvador-Bahia-Brasil. Salvador. UFBA. 2018.

SIMÕES, Júlio Assis; FRANÇA, Isadora Lins. Do "gueto" ao mercado. In: Homossexualismo em São Paulo e outros escritos. GREEN, James N.; TRINDADE, Ronaldo (Orgs.). São Paulo. Editora UNESP. 2005. p. 309-336.

\section{Entrevistas e reportagens de sites}

Entrevista com Rico Dalasam. Publicada no dia 08 de janeiro de 2015 no portal SPRESSOSP. Disponível em < http://spressosp.com.br/2015/01/08/o-fervo-e-protesto/ > . Acesso dia 23 de maio de 2016.

GONÇALVES, Juliana. Resistência impressa: Jornal O Clarim d'Alvorada. Reportagem disponível no sítio https://ceert.org.br/noticias/comunicacao-midia-internet/5999/resistencia-impressa-jornal-oclarim-dalvorada Acesso em 23 de maio de 2016.

Recebido em: 15/04/2019

Aceito em: 04/01/2020

Vol. 02, N. 04, Out. - Dez., $2019 \cdot$ www.revistas.unilab.edu.br/index.php/rebeh 